\title{
Features of Realization of Interdisciplinary Integration of Natural-Science and Technical Blocks of Disciplines
}

\author{
D.K. Afanasova \\ Z.Z. Utyaganova
}

Kumertausky branch of the Orenburg state university, 453300, Kumertau, 2nd Lane Sovietsky, 3b

\section{Doi:10.5901/mjss.2015.v6n6s3p71}

\begin{abstract}
In work experience, the realization of interdisciplinary integration of disciplines of natural science and technical blocks when training graduates of the construction direction in technical college is considered. Formation of professional competence of the Bachelor is one of the strategic tasks of higher education institution that decision is possible using interdisciplinary integration. In turn, interdisciplinary integration is realized by concentration round its kernel of the knowledge gained from areas of various disciplines. The programs constructed based on interdisciplinary integration allow not only to keep a fundamental basis of training courses but also to sate them with questions from disciplines of the corresponding profile of training. For a reflection of the level of interdisciplinary integration of disciplines of natural science and technical blocks, there is a need for creation of the programs uniting invariant and alternative components. The subject domain of these components in our work is the discipline of the mathematician. It is aware of mathematics professionally directed tasks for which decision the mathematical apparatus is necessary are considered. At the same time on courses of all professional and special disciplines, apply mathematical methods. Thus, the principles of continuity and continuity of training assuming collaboration of teaching structure of natural science and technical blocks are observed.
\end{abstract}

Keywords: professional competence, interdisciplinary integration, the professional, directed tasks.

\section{Introduction and Relevance}

Today in the labor market the enterprising, competitive bachelor capable independently of predicting and organizing the activity is demanded, competently to present the production and services, that is the graduate with the high level of professional competence. At a meeting of Council for science and education at the President on June 23, 2014 Vladimir Putin declared that leaders are those countries, which "are capable to create breakthrough technologies and on their basis to form own strong production base" and "quality of engineering shots to become one of the key factors of competitiveness of the state". One of the main features of scientific progress in the modern market relations is a synthesis of knowledge. The idea of a synthesis of knowledge along with other objective laws caused integration of scientific knowledge (Afanasova D.K., 2009). The idea of unity (integration) of scientific knowledge is shown in social, natural and technical science, in communication of theoretical and empirical knowledge, implementation of complex interdisciplinary researches, and application of mathematical models taking into account specifics of a subject of researches. Thus, the formation of professional competence of the bachelor-builder is impossible without realization of professionally directed training and the use of interdisciplinary integration of disciplines of natural science and technical blocks.

According to the academician of A. F. loffe: "it is impossible to teach the same physics - physics "in general", to the metallurgist and the electrician, the doctor, and the agronomist... For the agronomist of the physicist is a basis of an agrotechnology, a light-physiology for the doctor - biophysics. (But not a course of electrical equipment) has to give to the physicist's electrician the doctrine based on quantum mechanics about electrodes in a vacuum, semiconductors and insulators - understanding of mechanisms of magnetization and a ferroelectricity " (loffe A.F., 1951).

\section{Literature Review}

As the term "integration", it is understood: the concept meaning a ratio of connectivity of the separate differentiated parts and functions of system, an organism in whole, and also the process conducting to such state; the process of rapprochement and communication of Sciences happening along with processes and differentiations. (Big Soviet, 1969- 
1978)

We defined integration in educational activity as one of its parties connected with association of natural science and technical disciplines in a complex which result of functioning was a formation at the student of qualitatively new complete system of knowledge and abilities possessing new integrative properties unlike the components that are logging in.

Interdisciplinary integration in higher education from various points of view was considered in works of domestic scientists P. Z. Abdulaeva, V. S. Bezrukova, E. G. Vishnyakova, E.V. Galagan, V. A. Dalinegra, E. V. Perekhozheva, L. A. Shestakova, O. N. Shornikova, and also foreign scientists' Awbrey S.M, Dana D., Miller V.W., Robinson P., Ryan M.M., Scott, D.K., Grace D. J., Picard A., Huber M. T., Hutchings P., Shore, M. A., Walker, D., etc.

In pedagogical science interdisciplinary integration is defined as: "process of association of subject matters in the light of informative and technological problems" (Perekhozheva, E.V., 2012); process of the Commonwealth of the subjects reflecting the uniform, continuous and complete phenomena of professional activity (Shoshtaeva, E.B., 2003); Association of knowledge and practical actions at all stages of training of the expert, synthesis of all forms of occupations concerning each specific goal of education in higher education institution (Vishnyakova E.G., 2007); creation of complete system of structures of subject matters which would provide efficient use of communications between their contents (Abdullaeva P.Z., 2005).

Some scientists consider that "professional competence of students of technical colleges can start be formed already at the first-grade level using contextual training and interdisciplinary integration ..." (Danilova, O.V. et all, 2014).

According to teachers, interdisciplinary integration in education becomes a basis of personal self-realization and development of future expert (Shestakova, 2013 \& Utyaganova, 2009).

As process interdisciplinary integration consists of the following stages: definition is more than integration; selection of objects of integration; definition of a backbone factor; creation of structure of a new subject; choice of the maintenance of a subject according to science and the principles; a contents assessment on selection criteria; check on efficiency and correction of results (Figure 1).

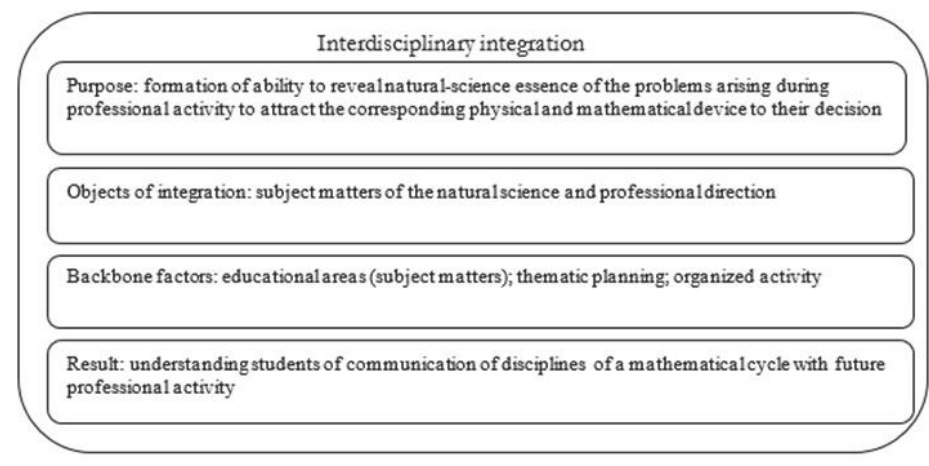

Figure 1 - Stages of interdisciplinary integration

According to L. A. Shestakova: "interdisciplinary integration is based on interpenetration of the maintenance of different subject matters and creation of the uniform educational space possessing the complete potential of development by means of use of innovative pedagogical and didactic methods and organizational forms of education and formation of competences" (Shestakova L.A., 2013)

On the other hand, it is established that between disciplines of natural science and technical blocks there is an intermediate link, which is conditionally designated by K. Shurakhanova, as field of cultural integration (Shurakhanova, K., 2003) which defines quality of process of formation of professional competence of the bachelor. Integration of subjects can exist and without this field, but then this integration deprives educational process of personal potential. This field acts as equilibrium point of two processes (figure 2). 


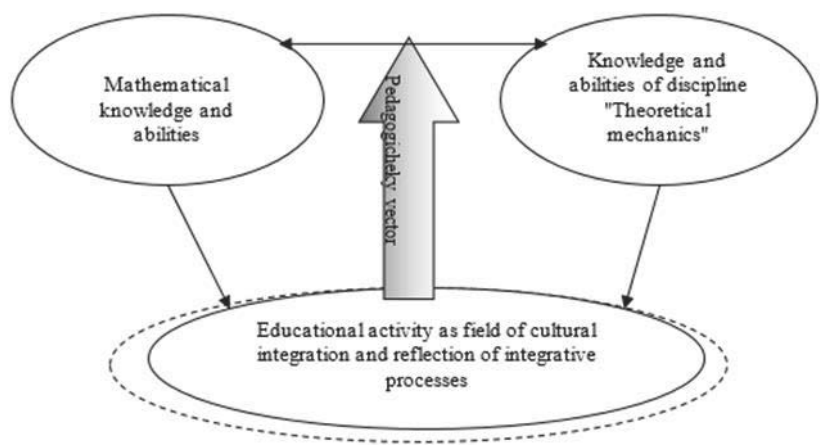

Figure 2 - Scheme of an associativity of vectors of formation of professional competence of process of integration of knowledge

For example, the integrating role of universality in disciplines of "mathematician" and "theoretical mechanics" is shown that they are not localized in some by one of these areas of culture, and penetrate all spheres. The system of universality includes knowledge of mathematics and theoretical mechanics in the generalized picture of the world of the person, outlook of an era.

According to K. Shurakhanova, these universalities become construction material of the inner intellectual world of the student, his culture of thinking. Therefore, it is possible to agree with V. L. Ginzburg that the mathematics from functional discipline becomes in modern conditions a basis fundamental. Without its device, it is impossible to prove a validity of the opened theories. (Afanasova, D. K., 2009)

Therefore, mathematics, being one of the main components of disciplines of the physicist, the information scientist, the chemistry, and, therefore, and technical disciplines, becomes a kernel of educational process of training of bachelors of the construction direction. Therefore, in modern integration processes of science and production, during an era of automation and a computerization special mathematical training of bachelor's is required.

\section{Methodology}

The mathematics course in system of natural sciences promotes formation of complete scientific idea of the world, expansion of the outlook, which is trained, and its spiritual component, intellectual and moral and ethical qualities that is caused by an enormous stock of common cultural values, which the science saved up during the active development.

Studying of mathematics makes a big contribution to the intellectual development of trainees and future bachelor's, promotes the formation of their scientific outlook. In the course of its studying students seize such receptions and methods of thinking as induction and deduction, generalization and a specification, the analysis and synthesis, classification and systematization, abstraction and analogy. The mathematics forms ability to prove and prove judgments develops logical and algorithmic thinking: ability to work on the set algorithm, to design new approaches to the different solution of tasks. Thus, in the course of studying of mathematics systematically and consistently, skills of brainwork develop scheduling, a search for rational ways of its performance, critical evaluation of the received results.

Let's consider interdisciplinary communications of disciplines of a natural-science cycle in federal state educational standards of higher education in the direction of Preparation 08.03.01 - Construction (Figure 3).

"Butt" discipline of a natural-science cycle is the course "Mathematics". It sets a subject round that material from other disciplines is grouped. Therefore, when studying concepts and definitions of mathematics we constantly pay attention of students to interdisciplinary subjects that is we pay attention to perspective communications. Interdisciplinary Communications generate integration of the disciplines united in a uniform course. It allows considering the taught disciplines from the different parties, to open all their interrelations with surrounding reality, and helps to reveal the importance of disciplines in the future profession. Therefore, one of the important problems of the process of realization of the integrated courses in training is the formation of professional competencies of future bachelors. 


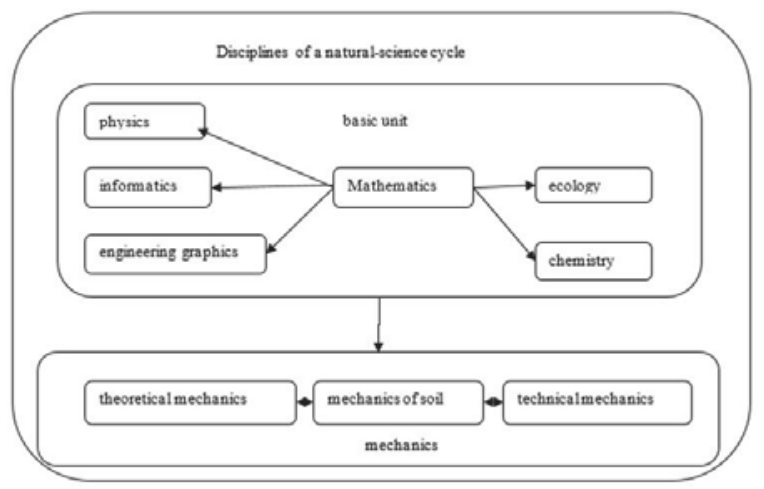

Figure 3 - Focused columns of conceptual interdisciplinary communications in federal state educational standards of higher education

Reflection of level of interdisciplinary integration of the block of natural science and technical disciplines requires creation of the programs uniting two courses: basic (an invariant component) and, supplementing it, integrative (an alternative component). One of conditions for invariant and alternative components is the existence of the general subject domain. Dual programs allow at preservation of a system of a fundamental training course of discipline, to connect with it questions from disciplines corresponding to a specialization profile. It promotes optimum realization of a combination of the fundamental and professionally directed alternative components of a training course of discipline. Let's consider the example of drawing up thematic planning of a practical training of discipline of "Mathematician" for the direction 08.03.01 - Construction (table 1).

Table 1 - Thematic planning of a practical training of discipline of "Mathematician" for the direction 08.03 .01 Construction.

\begin{tabular}{|c|c|c|c|}
\hline \multirow{2}{*}{$\begin{array}{l}\text { Analytical } \\
\text { geometry }\end{array}$} & \multirow{2}{*}{$\begin{array}{l}\text { Training and } \\
\text { Education } \\
\text { Module } \\
\end{array}$} & \multicolumn{2}{|l|}{$\begin{array}{l}\text { Approximate list of practical training } \\
\text { Purposes of a practical training }\end{array}$} \\
\hline & & Invariant component & Variable component \\
\hline \multirow[t]{2}{*}{1} & \multirow[t]{2}{*}{ Matrix algebra } & $\begin{array}{l}\text { 1. Matrixes. Determinants } \\
\text { Purpose: formation of knowledge and abilities to calculate } \\
\text { determinants of any order }\end{array}$ & $\begin{array}{l}\text { 1. Matrixes. Determinants } \\
\text { Purpose: to show calculation of determinant using the } \\
\text { appendices MS Excel, MATHCAD, (discipline of the } \\
\text { Information Scientist) }\end{array}$ \\
\hline & & $\begin{array}{l}\text { 2. Kramer's formulas and method of Gauss. } \\
\text { Purposes: formation of abilities of the decision of systems of the } \\
\text { algebraic equations by several methods. }\end{array}$ & $\begin{array}{l}\text { 2. Kramer's formulas and method of Gauss. } \\
\text { Purpose: to show application the decision of systems of } \\
\text { the linear equations in a subject processing of results } \\
\text { measurement and creation of correlation dependence by } \\
\text { method of the smallest squares (discipline Chemistry); } \\
\text { to teach to solve a system of the linear equations using } \\
\text { the MS Excel appendices, "MATHCAD" ( the discipline } \\
\text { of "Information Scientist") }\end{array}$ \\
\hline \multirow[t]{2}{*}{2} & \multirow[t]{2}{*}{$\begin{array}{l}\text { Analytical } \\
\text { geometry }\end{array}$} & $\begin{array}{l}\text { 1. A straight line on the plane. } \\
\text { Purposes: formation of abilities to draw up equations of a } \\
\text { straight line of different types; definitions of a relative } \\
\text { positioning of straight lines on the plane; definitions of corners } \\
\text { between straight lines on the plane. }\end{array}$ & $\begin{array}{l}\text { 1. A straight line on the plane. } \\
\text { Purpose: to show application at calculation of the } \\
\text { moments of inertia (discipline Theoretical mechanics); } \\
\text { to teach to define a corner between straight lines on the } \\
\text { plane by an MATHCAD package ( the discipline of } \\
\text { "Information Scientist") }\end{array}$ \\
\hline & & $\begin{array}{l}\text { 2. Straight line and the plane in space } \\
\text { Purposes: formation of abilities of drawing up equations of a } \\
\text { straight line of different types and equation of the plane; } \\
\text { definitions of a relative positioning of straight lines and planes in } \\
\text { space; definitions of corners between straight lines and the } \\
\text { planes in space. }\end{array}$ & $\begin{array}{l}\text { 2. Straight line and the plane in space } \\
\text { Purpose: to show application in a subject main types of } \\
\text { resistance (discipline Technical mechanics); } \\
\text { to teach to define a corner between straight lines in } \\
\text { space by an MATHCAD package (discipline of } \\
\text { "Information Scientist") }\end{array}$ \\
\hline
\end{tabular}

Table 2 in which application of elements of the section "Integral calculus" of a course of mathematics is shown is given as example it is aware of the general physics. The analysis of data of this table shows the need of realization of perspective, 
synchronous and successive interdisciplinary communications of courses of the general physics and mathematics. Similar tables of correlation between subjects of these courses are provided for the following sections of a course of the higher mathematics: "Linear algebra and analytical geometry", "Differential calculus", "The differential equations", "Theory of a field", "Probability theory".

Table 2 - Application is aware of the general physics of elements of the section "Integral calculus" of a course of the higher mathematics in technical college

\begin{tabular}{|llll|}
\hline Electrodynamics & Physics subjects (physical quantities, laws) & Mathematics subjects & \\
& & & \\
\hline Mechanics & Kinematics (the passable way, movement projection); dynamics (work of force) & Uncertain and certain \\
\hline Molecular Physics & Function of distribution of Maxwell on speeds and energy (finding of averages values) & integrals, geometrical & 2 \\
\hline Thermodynamics & Calculation of work of pressure force of gas, entropy calculation & sense of a certain integral \\
\hline Electrodynamics & Direct electric current (calculation of current through current density & & Double, threefold, \\
\hline Mechanics & Mechanics of a solid body (calculation of the moments of inertia of bodies of the correct & & planimetric, superficial \\
\hline Electrodynamics & geometrical form) & Direct electric current (electromotive force of a source of a direct current) & integrals \\
\hline
\end{tabular}

As one of conditions of interdisciplinary communications of disciplines of the natural-science cycle "Physicist" and "Mathematics" the problem of coordination of time of studying of concepts and the phenomena and their application in these courses acts. So, for example, when studying the concepts "uncertain integral", "certain integral", "multiple integral", according to the approved plan for a bachelor degree, the integral calculus in the program of mathematics is studied in the 2nd semester of the first course, and application of these concepts is aware to physics in 1 semester of the first course. Because of a gap in time between their studying it is expedient to pay, in any form of the organization of studies for mathematics (lecture, a laboratory and practical training, SRS), attention of students to the mathematical concepts applied in physics i.e. to pay attention to perspective communications.

For successful digestion of material of profile disciplines, the first-year student needs to seize the main methods of differentiation, integration, etc. For this purpose, in our opinion, the substantial course of mathematics in the system of training of the competent expert has to be exempted from strict proofs and is sated with various appendices. Objectively there is a need for purposeful integration of courses of the higher mathematics, physics and theoretical mechanics and informatics for technical college.

For development of discipline "Theoretical mechanics" knowledge, skills of the specified sections of disciplines of the mathematician, physicist, informatics (Table 3) are necessary.

Table 3 - Application is aware of theoretical mechanics of elements of sections of disciplines of mathematics, physics and informatics

\begin{tabular}{|c|c|c|}
\hline Informatics & Sections & Knowledge, abilities, skills \\
\hline \multirow[t]{4}{*}{ Mathematics } & linear algebra & skills of the decision of systems of the linear equations \\
\hline & vector algebra & Knowledge of linear operations over vectors, abilities to solve problems of this section \\
\hline & differential and integral calculus & to be able to differentiate, find certain integrals \\
\hline & differential equations & $\begin{array}{l}\text { to know the basic concepts; to have ideas of the common and private decision; to be able to solve } \\
\text { the differential equations of the first and the highest orders }\end{array}$ \\
\hline \multirow[t]{2}{*}{ Physics } & mechanics & $\begin{array}{l}\text { nobility basic concepts of the section } \\
\text { to know laws of mechanics of a rotary motion }\end{array}$ \\
\hline & dynamics & $\begin{array}{l}\text { to be able to use physical laws of the electric and magnetic phenomena at the solution of standard } \\
\text { tasks }\end{array}$ \\
\hline \multirow[t]{2}{*}{ Informatics } & computers and computer networks & to have skills of work on the computer and the Internet \\
\hline & $\begin{array}{l}\text { the applied program } \\
\text { providing }\end{array}$ & $\begin{array}{l}\text { to have skills of the use of the applied software (universal mathematical programs, word } \\
\text { processors, editors of formulas, etc.) }\end{array}$ \\
\hline
\end{tabular}

Apparently from this table when studying a course of theoretical mechanics it is necessary to realize intersubject communications of disciplines of the higher mathematics, physics and informatics.

At a meeting of Council for science and education at the President on June 23, 2014 it was said that "it is necessary to change structure of educational process in technical colleges, the big emphasis needs to be placed on a practical training - of course, not to the detriment of the theory, not at the expense of lecture work, nevertheless, more 
practice has to be, it is more than approaches to scientific researches of students and teachers". For technical specialties it is necessary to strengthen physical and mathematical preparation, not at the expense of increase in a number of hours, and due to systematicity of knowledge - there is a kernel of knowledge, and all others act with it in more and more close connections.

Students of the technical direction need to be trained in mathematical modeling of professional tasks both in mathematical courses and in all professional and special disciplines. For this purpose, for example, it is aware of mathematics it is necessary to consider professionally focused tasks for which decision the mathematical apparatus is used, and in courses of all professional and special disciplines to use mathematical methods, i.e. the principles of a continuity and continuity of training which assume collaboration of specialists in natural science and technical blocks have to be observed( Ismagilova E.I., 2009).

The professionally focused task is understood as a task of the professional contents for which decision the mathematical apparatus is used, promoting the professional development of the identity of the expert. (Afanasova D. K., 2009)

Let's review an example professional focused tasks when studying the section "Differential calculus":

"The manipulator of the robot represents the flat mechanism. Links of this device form "a mechanical hand" with capture at a point $A$. Link $O A=1 \mathrm{~m}$ of this device represents a crank and makes a rotary motion round an axis. The angular speed of crank changes under the law $\omega=2 \sin \frac{\pi t}{4}$ (M). The movement of a point of $A$ lasts 1 s. It is required to define tangent acceleration of a point A».

Decision: We define tangent acceleration of a point $a_{\tau}=R \cdot \varepsilon$. We define angular acceleration of a point $\varepsilon=\omega^{\prime}=\frac{d \omega}{d t}$

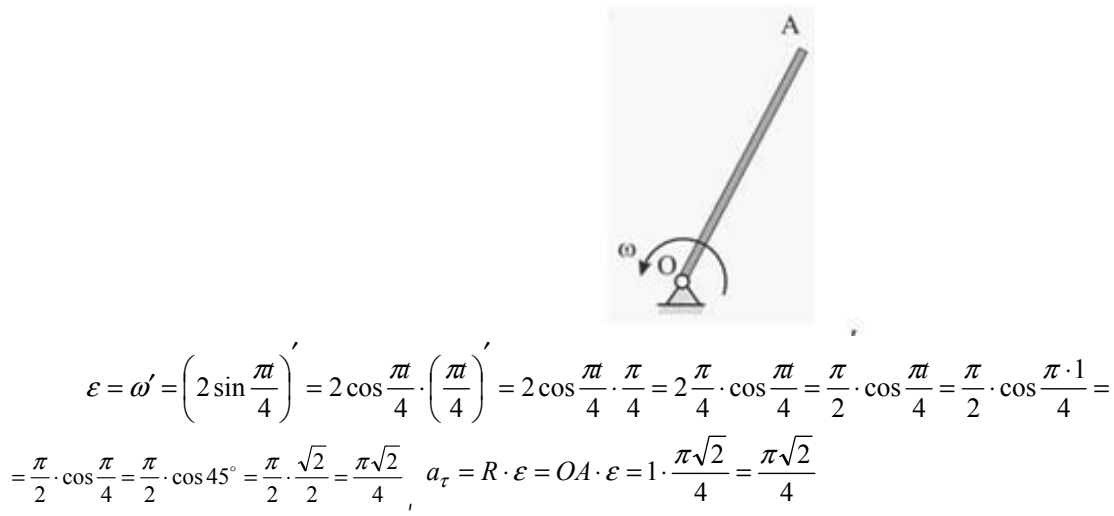

At the solution of this task, apply the concepts "derivative", "speed". The skill of calculation of difficult derivative function is at the same time fulfilled.

\section{Conclusions}

In modern conditions, great demands are made of training of the university graduate. The main indicator of qualification of the modern bachelor is his professional competence showing the level of formation of abilities to apply the gained knowledge to decision-making in professional reality. The creative, initiative, self-actualizing personality can develop and be brought up only in the conditions of the indissoluble pedagogical process constructed on the uniform principles and methods. Therefore when receiving the higher education from the first days of training, it is necessary to pay significantly more attention to interdisciplinary communications.

\section{References}

Abdullaeva, P.Z. (2005) Realization of interdisciplinary technology in the formation of information culture of lawyers in the course of vocational training: the thesis of the candidate of the pedagogical. Sciences: 13.00.08 / P.Z. Abdullaeva. Makhachkala. pp. 153.

Afanasova, D.K. (2009) Formation of professional competence of the economist of educational and research activity: the thesis of the 
candidate of the pedagogical. sciences13.00.08 / Afanasova Dinara Kamilyevna. Orenburg: Orenburg state pedagogical university. pp. 191.

Bezrukova, V.S. (1994) Integration processes in the pedagogical theory and practice / V. S. Bezrukova. Yekaterinburg: Publishing house SPEAK HOARSELY. pp. 192.

Big Soviet Encyclopedia: in 30 t. T. 10 (1972) / under edition. A. M. Prokhorova. M. T.10. pp. 307.

Vishnyakova, E.G. (2007) An interdisciplinary network educational and methodical complex as means of an increase of learning efficiency in higher education institution: abstract of the thesis of the candidate of pedagogical sciences: 13.00 .08 / E.G. Vishnyakova. Volgograd, 2007. pp. 22.

Galagan, E.V. Problems of realization of interdisciplinary integration in the educational process of higher education institution. [electronic resource]http://litterref.ru/otrrnaujgqasjgeotr.html

Gogoleva, I.V. (2014) Interdisciplinary integration in the educational activity of students of higher education institution / I. V. Gogoleva//Global scientific potential. №11(44). pp. 56-59.

Dalinger, V.A. (2002) Mathematical modeling as integration tool of natural-science and mathematical disciplines / V. A. Dalinger/leducation Integration. No. 4. pp. 106-112.

Danilova, O.V. (2014) Formation of professional competence of students of technical colleges using interdisciplinary integration / O.V. Danilova, N.D. Zinnatullin, G.R. Timerbayev//Discussion. No. 5 (46). pp. 110-115.

Isaeva, O.N. (2008) Integration processes in the field of education as a factor of the formation of world educational system: analysis of world tendencies//Russian scientific magazine. No. 3. pp. 161-170.

Ismagilova, E.I. (2009) Integrative and modular component of a professional orientation of training in mathematics of future engineers of radio engineering specialties: abstract of the thesis of the candidate of pedagogical sciences: 13.00 .02 / E. I. Ismagilova. Yaroslavl. pp. 22.

Ioffe, A.F. (1951) O teaching physics at the higher technical school / A. F. loffe//the Bulletin of the higher school. No. 10. pp. 17-18.

Kantsur, A.G. (2014) Formation of ligvo-methodical competence of students in the conditions of interdisciplinary integration [An electronic resource] / A. G. Kantsur, M. A. Mosina//Modern problems of science and education. №1. -http://www.scienceeducation.ru/pdf/2014/1/72.pdf.

Kovyneva, I.A. (2015) Interdisciplinary integration of Russian and profile disciplines in medical school when training foreign students in language of specialty (from experience of teaching) [An electronic resource] / I.A. Kovyneva, N.E. Petrova//Modern problems of science and education. №1. http://www.science-education.ru/121-18541.

The concept of the Federal target program of a development of education for 2016-2020: official. text [an electronic resource]. Moscow: name of the magazine, 2014. pp. 150. http://government.ru/media/files/mlorxfXbbCk.pdf.

Perekhozheva, E.V. (2012) Formation of professional competence of students of technical colleges on the basis of interdisciplinary integration: abstract of the thesis. Candidate of pedagogical sciences 13.00.08 / Perekhozheva Elena Vladimirovna. Chita: Transbaikal state humanitarian and pedagogical university of G. Chernyshevsky's N. 2012. pp. 29.

Stepanova, M.M. (2014) Foreign language as means of interdisciplinary integration: from school to a magistracy / M. M. Stepanova//the Young scientist. No. 4. pp. 1244-1246.

Utyaganova, Z.Z. (2009) "An image of the future" as a condition of self-realization of the student / Z. Z. Utyaganova//the Higher education in Russia. No. 5. pp. 154-157.

Shestakova, L.A. (2013) The theoretical bases of interdisciplinary integration in the educational process of higher education institutions/L. A. Shestakova//Bulletin of the Moscow University of the Name S.Yu. Witte. Series 3: Pedagogics. Psychology. Educational resources and technologies. No. 1(2). pp. 47-52.

Shornikova, O.N. (2010) Tekhnologiya of the formation of information competence of students on the basis of interdisciplinary integration//Modern high technologies. 2010. № 12. pp. 83-85.

Shoshtayeva, E.B. (2003) Integrated technology of training as the basis of improvement of the quality of educational process: abstract of the thesis of the candidate of pedagogical sciences: 13.00.01 / E. B. Shoshtayeva. Karachayevsk. pp. 23.

Shurkhanova, K. (2003) Formation of the culture of thinking of students in the course of integration of knowledge: abstract of the thesis of the candidate of pedagogical sciences: 13.00.01/K. Shurakhanova. Orenburg, pp. 23.

Awbrey, S.M, Dana, D., Miller, V.W., Robinson, P., Ryan, M.M. \& Scott, D.K. (Eds.) (2006). Integrative Learning and Action: A Call to Wholeness (Studies in Education and Spirituality). New York: Peter Lang Publ.

Grace, D.J., \& Picard, A. (2001). An Experimental Approach to Integrating Mathematics and Literacy Methods Courses. Action in Teacher Education, 23(1), 29-36.

Huber, M.T., \& Hutchings, P. (2004). Integrative Learning: Mapping the Terrain. The Academy in Transition. Washington, DC.: Association of American Colleges and Universities.

Shore, M.A., \& Shore, J.B. (2003). An Integrative Curriculum Approach to Developmental Mathematics and the Health Professions Using Problem Based Learning. Mathematics and Computer Education, 37(1), 29-38.

Scott, D.K. (2002). General Education for an Integrative Age. Higher Education Policy, 15(1), 7-18.

Walker, D. (1996). Integrative Education. Eugene OR: ERIC Clearinghouse on Educational Management. 